\title{
In situ Crystal Growth Rate Distributions of Active Pharmaceutical Ingredients
}

Sreya Sarkar ${ }^{1, \$}$, Zhengtian Song ${ }^{1, \star}$, Scott R. Griffin ${ }^{1}$, Nita Takanti ${ }^{1}$,Andrew D. Vogt ${ }^{2}$, Gerald D. Danzer $^{2}$, Alexander Ruggles ${ }^{2}$, Garth J. Simpson ${ }^{1 *}$

${ }^{1}$ Department of Chemistry, Purdue University,560 Oval Drive, West Lafayette, IN 47906

${ }^{2}$ AbbVie Inc., $1 \mathrm{~N}$ Waukegan Road, North Chicago, IL 60064

*gsimpson@purdue.edu

$\$$ These authors contributed equally to this work

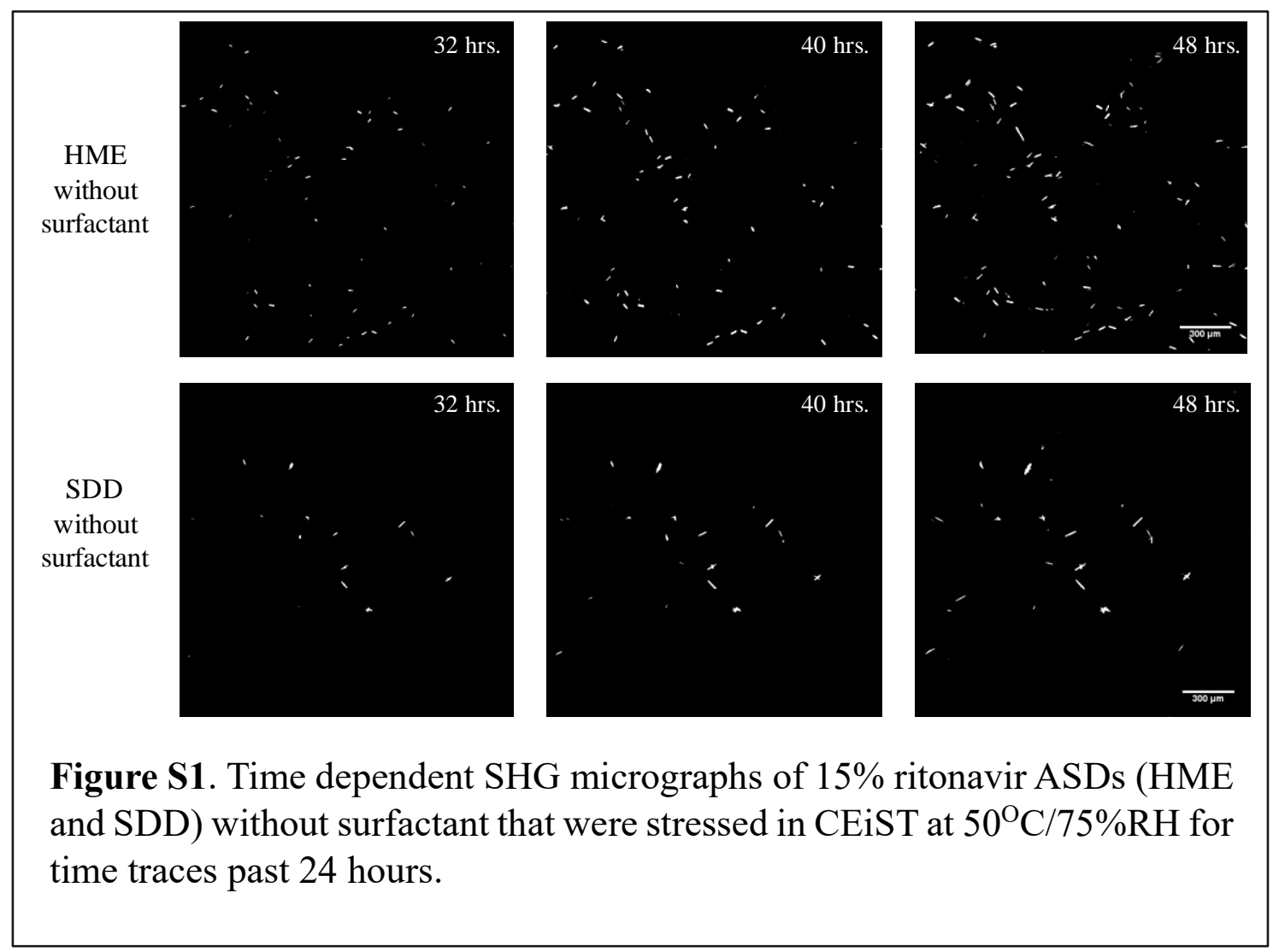




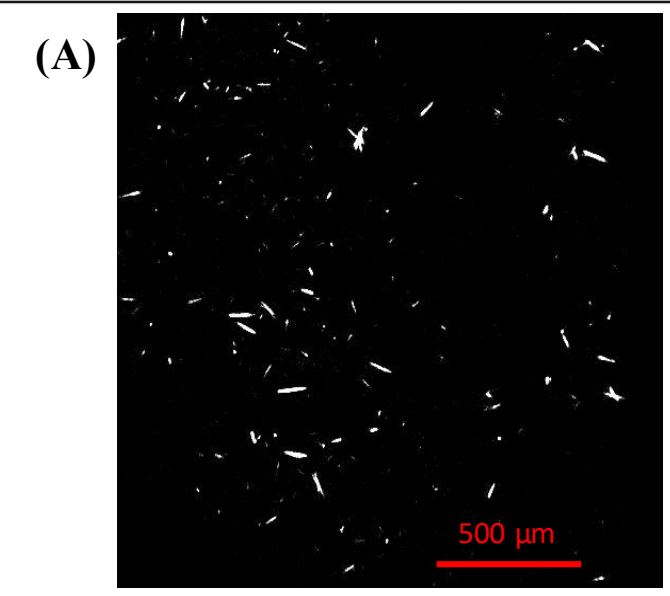

(B)

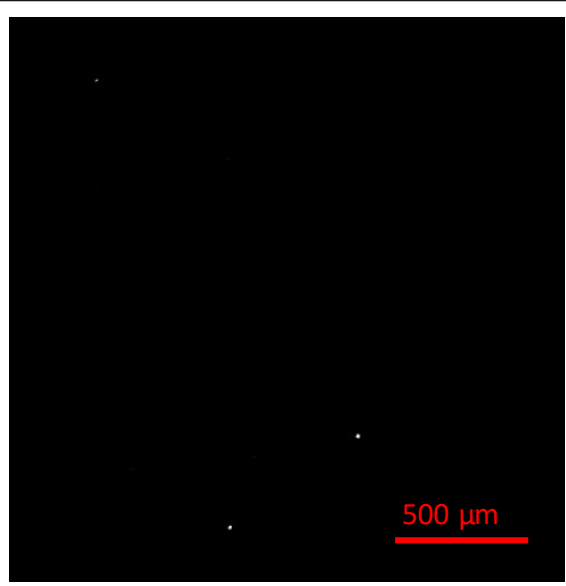

Figure S2. (A) SHG image of $15 \%$ HME ritonavir after being taken out of $50^{\circ} \mathrm{C} / 75 \% \mathrm{RH}$ standard chamber every one hour and staying at room temperature for $15 \mathrm{~min}$ each time for a duration of 5 hours, (B) SHG image of $15 \% \mathrm{HME}$ ritonavir after staying in $50^{\circ} \mathrm{C} / 75 \% \mathrm{RH}$ standard chamber for 5 hours directly. 


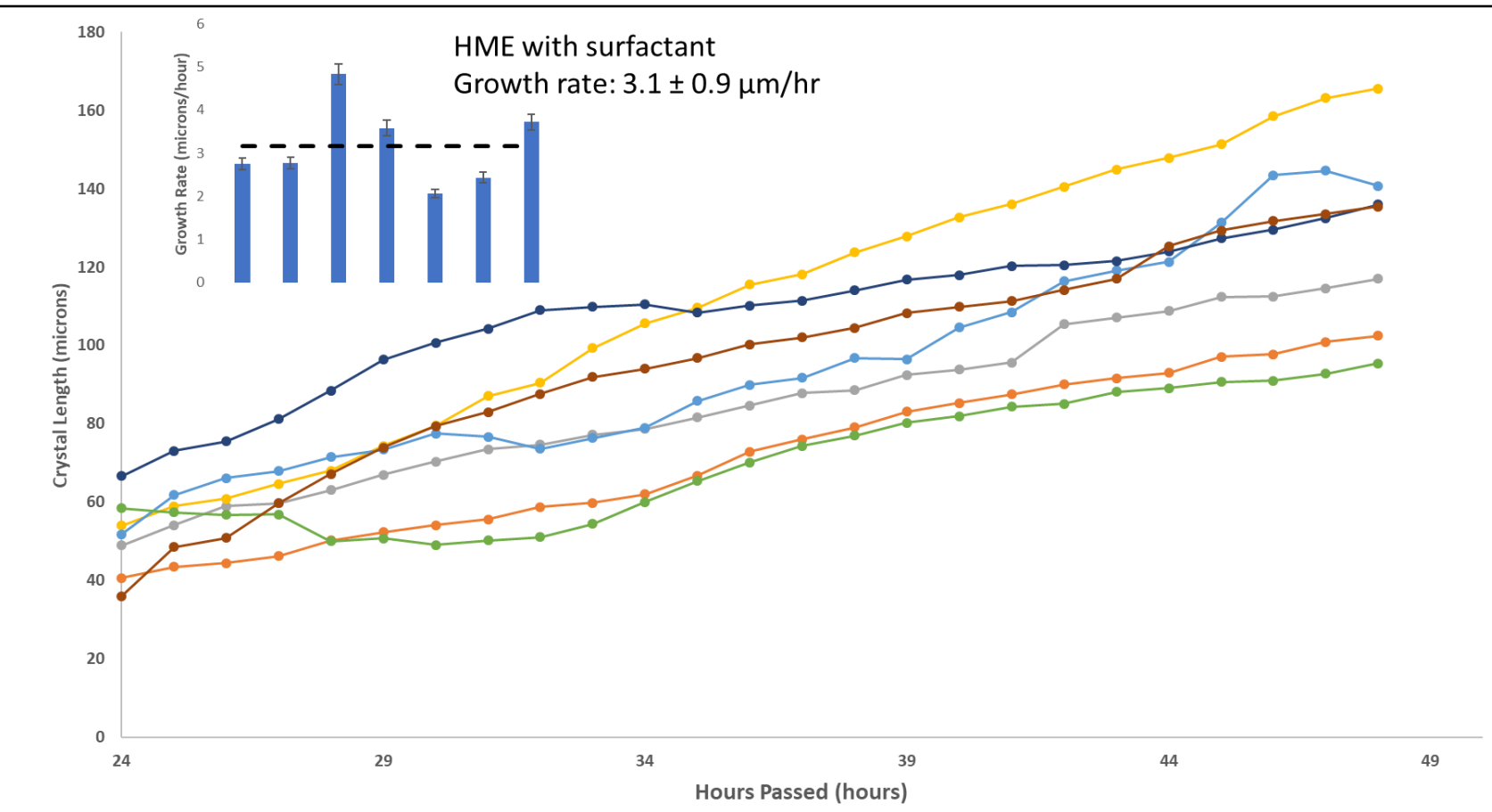

Figure S3. Crystals seeded on the surface were monitored over time to obtain growth rates of individual crystals aligned on the same plane. 